\title{
Is the Mississippian Bowland Shale an End-Member?
}

J. EMMINGS ${ }^{1,2 *}$, S. Poulton ${ }^{3}$, S. DAVIES ${ }^{2}$, C. VANE ${ }^{1}$, G. JENKIN ${ }^{2}$, M. STEPHENSON ${ }^{1}$, J. HENNISSEN ${ }^{1}$,

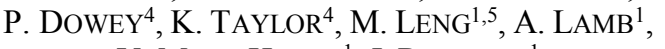
V. MOSS-HAYES ${ }^{1}$, J. RUSHTON ${ }^{1}$

${ }^{1}$ British Geological Survey, Keyworth, Nottingham, NG12 5GG, UK.*correspondance: josmin65@bgs.ac.uk ${ }^{2}$ School of Geography, Geology and the Environment, University of Leicester, Leicester, LE1 7RH, UK.

${ }^{3}$ School of Earth and Environment, University of Leeds, Leeds, LS2 9JT, UK.

${ }^{4}$ Department of Earth and Environmental Sciences, The University of Manchester, Oxford Road, Manchester, M13 9PL, UK.

${ }^{5}$ Centre for Environmental Geochemistry, Sutton Bonington Campus, University of Nottingham, Sutton Bonington, Leicestershire, LE12 5RD, UK.

Here we explore our recent advances in understanding the processes which operated during deposition and burial of the UK Mississippian Bowland Shale. Sedimentary facies include carbonate-rich, macrofauna-bearing and/or lenticular mudstones, and mass transport deposits; typically associated with normal marine water column conditions, anoxic bottom waters, and methanogenesis intermittently close to seabed. Most anoxic facies contain pervasive early diagenetic quartz crysts, which apparently 'buttress' the sedimentary matrix. We show falling sea level triggered a switch in the style of bottom water redox conditions, from (i) periods of high sea level associated with anoxic and at least intermittently sulphidic bottom water conditions, in general with a 'stable' water column chemocline, to; (ii) periods of falling sea level defined by 'redox oscillation' between ferruginous and sulphidic conditions within shallow sediment pore waters. The Bowland Shale may define an end-member black shale with the following characteristics; (i) productivity-driven bottom water anoxia within weakly restricted, and likely thermally stratified basins; (ii) a relatively high mean sediment accumulation rate linked to a tropical delta system; (iii) therefore high loadings of biogenic silica, labile OM and metal oxides, with high potential for precipitation of authigenic silicates; (iv) a complex bathymetric setting, with high capacity for temporary storage of reactive $\mathrm{Fe}$ on shelves; (v) high frequency, high magnitude sea level fluctuation which promoted pulsed transfer of reactive Fe from shelves to basins, and as a result the ability to; (vi) develop oscillatory redox conditions, and; (vii) host (and possibly transfer) a relatively large volume of early diagenetic fluids. 